\author{
Jürgen Barwing \\ Markus Ambold \\ Nadine Linden \\ Michael Quintel \\ Onnen Moerer
}

\section{Evaluation of the catheter positioning for neurally adjusted ventilatory assist}

Received: 26 April 2009

Accepted: 9 July 2009

Published online: 4 August 2009

(C) The Author(s) 2009. This article is published with open access at Springerlink.com
J. Barwing - M. Ambold · N. Linden ·

M. Quintel · O. Moerer (四)

Department of Anaesthesiology,

Emergency and Intensive Care Medicine,

Georg-August University of Göttingen,

Robert-Koch-Str. 40, 37075 Göttingen,

Germany

e-mail: omoerer@gwdg.de

Tel.: +49-551-399561
Abstract Purpose: During neurally adjusted ventilatory assist (NAVA) the ventilator is driven by the patients electrical activation of the diaphragm (EAdi), detected by a special esophageal catheter. A reliable positioning of the EAdi-catheter is mandatory to trace a representative EAdi signal. We aimed to determine whether a formula that is based on the measurement from nose to ear lobe to xiphoid process of the sternum (NEX distance) modified for EAdi-catheter placement $\left(\mathrm{NEX}_{\mathrm{mod}}\right)$ is sufficient for predicting the accurate catheter position. Methods: Twenty-six patients were enrolled in this study. The optimal EAdi-catheter position (OPT) was defined by: (1) stable EAdi signal, (2) electrical activity highlighted in central leads of the catheter positioning tool, and (3) absence of p-wave in distal lead. Afterwards $\mathrm{NEX}_{\text {mod }}$ was calculated and compared to the OPT finding. Results: At $\mathrm{NEX}_{\text {mod }}$ the EAdi signal was suitable for running NAVA in 18 out of 25 patients (72\%). $\mathrm{NEX}_{\text {mod }}$ was identical with OPT in four patients (16\%). NAVA was possible in all patients at OPT. Median OPT position was $2 \mathrm{~cm}$ caudal of the $\mathrm{NEX}_{\text {mod }}$ ranging from $3 \mathrm{~cm}$ too cranial to a position $12 \mathrm{~cm}$ too caudal $(P<0.01)$. In one patient excluded from further analysis EAdicatheter placement led to the diagnosis of bilateral injury of the phrenic nerves. Conclusions: EAdi-catheter placement based on the NEX $\mathrm{Nod}_{\text {for- }}$ mula allows running NAVA in about two-thirds of all patients. The additional tools provided are efficient and facilitate the correct positioning of the EAdi-catheter for neurally adjusted ventilatory assist.

Keywords Neurally adjusted ventilatory assist (NAVA) . Neural control $\cdot$ Electrical activation of the diaphragm (EAdi)

\section{Introduction}

Neurally adjusted ventilatory assist (NAVA) is a new mode of assisted mechanical ventilation [1-5]. During NAVA the ventilator is triggered by the electrical activity of the diaphragm (EAdi), assessed by a special gastric tube (EAdicatheter). Patient-ventilator synchronization is increased by neural control [6]. Pressure support is applied in proportion to the amplitude of the EAdi, which represents direct control by the patients own respiratory center $[1-5,7]$.
During NAVA reliable positioning of the EAdi-catheter is mandatory in order to trace a representative EAdi signal from the diaphragm. One method to predict the correct position of a gastric feeding tube is based on the measure from the nose to the ear lobe to the xiphoid process of the sternum (NEX distance) [8]. Using the NEX distance the gastric feeding tube was placed trans nasally more than $10 \mathrm{~cm}$ into the stomach in $26 \%$ of 99 adult cadavers and five normal adult volunteers. For EAdi-catheter positioning the manufacturer suggests a 
modified NEX distance which aims to predict the ideal position of the electrode array. There are no studies that evaluated this approach. Therefore we aimed to determine whether or not it is sufficient to place the catheter purely by using the modified NEX distance.

\section{Methods}

This observational study was performed after ethics committee approval at the anaesthesiological ICU, University of Goettingen, Germany. NAVA was initiated with the intention to improve patient respirator synchrony and to facilitate respirator weaning.

Patients were treated with a ventilator capable of NAVA (Servo-i, Maquet Critical Care, Solna, Sweden). Pressure support ventilation was used prior to EAdicatheter positioning.

Patients were in supine position with the upper part of the body elevated in a $30^{\circ}$ angle and gastric content was drained via the nasogastric tube. Afterwards the standard tubing was replaced by the EAdi-catheter (16 french diameter, $125 \mathrm{~cm}$ long; Maquet Critical Care, Solna, Sweden), inserted nasally to a maximum distance of $80 \mathrm{~cm}$.

For EAdi measurement this tube is mounted with an electrode array of nine electrode rings on the distal part of the catheter at intervals of $16 \mathrm{~mm}$, starting $120 \mathrm{~mm}$ from the tip.

Catheter positioning was monitored by a special tool implemented in the ventilator. It displays an EAdi curve and four raw leads not filtered for ECG activity. The electrical activity used for generating the EAdi signal is highlighted. The position of the electrodes in relation to the heart and diaphragm can be estimated by evaluating the different leads for presence/absence of $p$-wave and QRS complex. During the placement procedure the catheter was pulled out in steps of $1 \mathrm{~cm}$. EAdi signal and electrical activity from raw leads were recorded at each step using special software (NAVA tracker, Maquet Critical Care, Solna, Sweden) for offline analysis until ECG-signals disappeared. The "optimal" catheter position (OPT) was identified by checking the recording for the following three criteria: (1) stable EAdi signal, (2) electrical activity highlighted in central leads of the catheter positioning tool, and (3) absence of p-wave in distal lead. Within the catheter positions that fulfilled the above mentioned criteria we chose the one with the maximum EAdi value as OPT.

Afterwards we calculated the insertion distance of the EAdi-catheter $\left(\mathrm{NEX}_{\mathrm{mod}}\right)$ by the formula proposed by the manufacturer (Maquet catheter packaging).

$$
\begin{aligned}
\mathrm{NEX}_{\text {mod }}= & (\mathrm{NEX} \times 0.9) \\
& +18(\text { for the } 16 \mathrm{~F} . \text { EAdi-catheter })
\end{aligned}
$$

In the formula the measured NEX distance is multiplied by a correction factor (NEX $\times 0.9$ for nasal catheter insertion) in order to predict the distance to the crural diaphragm. Depending on the catheter size used, a constant is added to compensate for the varying electrode array localisation ( " +18 " $\mathrm{cm}$ for the $16 \mathrm{~F}, 125 \mathrm{~cm}$ catheter).

For NEX measurement the patient was placed supine and the outer canthus of the patient's eye was vertically aligned with the tragus of the ear to decrease errors resulting from head tilt.

Data on $\mathrm{NEX}_{\text {mod }}$ and OPT position were compared by Wilcoxon matched pairs.

\section{Results}

Patient characteristics of 26 enrolled patients are presented in Table 1.

EAdi-catheter placement was possible in all patients and enteral nutrition via the EAdi-catheter was continued uneventfully during NAVA.

p-Waves were absent in seven patients (six due to atrial fibrillation). In one patient $(25+1)$, treated with an extracorporal cardiac assist device, there was no detectable EAdi signal although the patient was able to trigger pressure support ventilation (PSV) by his auxiliary respiratory muscles. Since cervical magnetic stimulation of the phrenic nerves did not result in any diaphragmatic response, bilateral injury was suspected and the patient excluded from further data analysis.

In patient 19 the EAdi-catheter was positioned endotracheally first. The suspected malposition was detected at once by complete lack of stable EAdi and ECG-signals and corrected immediately after verification by chest X-ray.

In patient 24 ( 8 years post gastrectomy) the catheter positioning tool did not highlight the electrical activity of the diaphragm comprehensibly although it was present.

At $\mathrm{NEX}_{\text {mod }}$ the EAdi signal was suitable for running NAVA in 18 patients (72\%). The remaining seven patients $(28 \%)$ had an inadequate signal quality, thus NAVA was impossible (Fig. 1). Six of these patients showed the alarm "check catheter position". NAVA was possible at OPT position in all patients. The NEX $\mathrm{Nod}_{\text {mod }}$ position was identical with the OPT position in four patients $(16 \%)$. In general we found the OPT position caudal of the $\mathrm{NEX}_{\text {mod }}$ (Fig. 2). The median difference was $2 \mathrm{~cm}$ and the difference ranged from $3 \mathrm{~cm}$ too cranial to a position $12 \mathrm{~cm}$ too caudal $(P<0.01)$. Patient 7 (12 cm difference) had a short neck and low lying ears which led to the suspected diagnosis of a Laurence-Moon-Biedl-Bardet-Syndrom [9, 10] and should be regarded as an outlier. At $\mathrm{NEX}_{\text {mod }}$ position the 
Table 1 Basic patient characteristics including gender, age, height, body mass index (BMI), Reason for ICU admission (Reason adm.), severity off illness on admission evaluated by SAPS II, positive endexpiratory pressure (PEEP) during EAdi-catheter placement and heart rhythm

\begin{tabular}{|c|c|c|c|c|c|c|c|c|c|c|c|}
\hline Patient & Gender & $\begin{array}{l}\text { Age } \\
\text { (years) }\end{array}$ & $\begin{array}{l}\text { Height } \\
(\mathrm{cm})\end{array}$ & BMI & $\begin{array}{l}\text { Reason } \\
\text { adm. }\end{array}$ & SAPS II & $\begin{array}{l}\text { PEEP } \\
\left(\mathrm{cmH}_{2} \mathrm{O}\right)\end{array}$ & $\begin{array}{l}\text { Heart } \\
\text { rhythm }\end{array}$ & $\begin{array}{l}\mathrm{NEX}_{\text {mod }} \\
(\mathrm{cm})\end{array}$ & $\begin{array}{l}\text { OPT } \\
(\mathrm{cm})\end{array}$ & $\begin{array}{l}\text { Diff. } \\
(\mathrm{cm})\end{array}$ \\
\hline 1 & $\mathrm{M}$ & 56 & 182 & 37.7 & $\mathrm{CHD}$ & 29 & 8 & SR & 70.2 & 67 & -3.2 \\
\hline 2 & M & 41 & 190 & 23.5 & TBI & 51 & 8 & SR & 66.6 & 71 & 4.4 \\
\hline 3 & $\mathrm{~F}$ & 76 & 165 & 29.4 & CPR & 65 & 8 & SR & 56.7 & 65 & 8.3 \\
\hline 4 & $\mathrm{~F}$ & 79 & 150 & 29.3 & AS & 52 & 11 & SR & 60.3 & 60 & -0.3 \\
\hline 5 & M & 33 & 190 & 27.7 & TBI & 48 & 7 & SR & 66.6 & 66 & -0.6 \\
\hline 6 & $\mathrm{~F}$ & 75 & 160 & 30.1 & ARDS & 79 & 10 & Afib & 58.5 & 61 & 2.5 \\
\hline 7 & $\mathrm{~F}$ & 72 & 160 & 25.4 & Trauma & 66 & 6 & SR & 54 & 66 & 12 \\
\hline 8 & M & 73 & 174 & 26.4 & TBI & 59 & 8 & SR & 65.7 & 66 & 0.3 \\
\hline 9 & M & 41 & 190 & 24.9 & $\mathrm{AI}$ & 54 & 8 & Afib & 69.3 & 71 & 1.7 \\
\hline 10 & $\mathrm{M}$ & 66 & 174 & 29.4 & Trauma & 32 & 8 & SR & 66.6 & 68 & 1.4 \\
\hline 11 & $\mathrm{M}$ & 63 & 170 & 26.0 & TBI & 51 & 10 & SR & 61.2 & 63 & 1.8 \\
\hline 12 & M & 78 & 176 & 24.2 & CHD & 38 & 8 & Afib & 61.8 & 66 & 4.2 \\
\hline 13 & $\mathrm{~F}$ & 64 & 162 & 24.8 & $\mathrm{ARF}$ & 59 & 10 & SR & 58.2 & 57 & -1.2 \\
\hline 14 & $\mathrm{M}$ & 86 & 175 & 26.1 & Trauma & 63 & 8 & SR & 64.8 & 69 & 4.2 \\
\hline 15 & $\mathrm{~F}$ & 87 & 163 & 24.1 & $\mathrm{CHF}$ & 45 & 8 & SR & 59 & 63 & 4 \\
\hline 16 & $\mathrm{M}$ & 54 & 189 & 23.8 & TBI & 20 & 7 & SR & 65 & 67 & 2 \\
\hline 17 & $\mathrm{~F}$ & 64 & 165 & 22.0 & SAH & 58 & 8 & SR & 62.1 & 65 & 2.9 \\
\hline 18 & M & 68 & 170 & 29.4 & CHD & 19 & 8 & SR & 63.9 & 66 & 2.1 \\
\hline 19 & $\mathrm{M}$ & 82 & 178 & 27.5 & CHD & 24 & 10 & Afib & 71.1 & 69 & -2.1 \\
\hline 20 & $\mathrm{M}$ & 78 & 167 & 19.7 & AS & 35 & 6 & Afib & 61.2 & 61 & -0.2 \\
\hline 21 & M & 35 & 180 & 23.1 & Sepsis & 47 & 12 & SR & 68.4 & 69 & 0.6 \\
\hline 22 & $\mathrm{~F}$ & 64 & 169 & 26.6 & Sepsis & 93 & 10 & Afib & 63.9 & 65 & 1.1 \\
\hline 23 & $\mathrm{~F}$ & 81 & 158 & 22.0 & CHD & 75 & 8 & SR & 61.2 & 66 & 4.8 \\
\hline 24 & $\mathrm{M}$ & 77 & 165 & 29.4 & $\mathrm{ICH}$ & 53 & 10 & SR & 63 & 67 & 4 \\
\hline 25 & $\mathrm{M}$ & 40 & 185 & 27.8 & Trauma & 64 & 12 & SR & 69 & 69 & 0 \\
\hline $25+1$ & $\mathrm{M}$ & 40 & 179 & 32.6 & $\mathrm{CHF}$ & 72 & - & BVAD & - & - & - \\
\hline $\begin{array}{l}\text { Median } \\
\qquad\left(\mathrm{Q}_{25} / \mathrm{Q}_{75}\right)\end{array}$ & - & $\begin{array}{l}68 \\
(55 / 78)\end{array}$ & $\begin{array}{l}170 \\
\quad(165 / 180)\end{array}$ & 26 & - & ${ }^{52}(40 / 64)$ & $8(8 / 10)$ & - & $\begin{array}{l}63.9 \\
\quad(61.2 / 66.6)\end{array}$ & $\begin{array}{l}66 \\
(65 / 68)\end{array}$ & $1.8(0 / 4)$ \\
\hline Mean \pm SD & - & $65.3 \pm 16.0$ & $172.3 \pm 11.0$ & $26.4 \pm 3.6$ & - & $51.2 \pm 18.0$ & $8.7 \pm 1.6$ & - & $63.5 \pm 4.3$ & $65.7 \pm 3.3$ & $2.2 \pm 3.1$ \\
\hline
\end{tabular}

The median exact catheter position estimated by $\mathrm{NEX}_{\text {mod }}$ was $64 \mathrm{~cm}$ compared to $66 \mathrm{~cm}$ detected by optimal catheter positioning (OPT) based on a stable EAdi signal, electrical activity highlighted in the central leads of the catheter positioning tool and the absence of p-waves in the distal lead

$M$ male, $F$ female, $C H D$ coronary heart disease, $T B I$ traumatic brain injury, $C P R$ post cardiopulmonary resucitation, $A S$ aortic valve stenosis, ARDS adult

catheter positioning tool highlighted the central leads in ten cases $(42 \%)$. p-Wave was absent in the distal lead in nine cases ( $47 \%$ of patients with p-waves) (Fig. 1). The criterion "highlighted electrical activity in central leads" narrowed the OPT position down to an area of 2-7 cm. In consideration of "absence of p-wave", the OPT position could additionally be narrowed down to an area of $2-5 \mathrm{~cm}$.

\section{Discussion}

During NAVA, correct placement of the EAdi-catheter is mandatory to deduce a reliable EAdi signal for respirator control. The modified NEX distance successfully predicted the EAdi-catheter insertion distance in 18 of 25 patients and was identical with the OPT position in four patients. In combination with the catheter positioning tool, catheter placement was possible in all 25 patients. respiratory distress syndrome, Trauma severe trauma other than TBI, $A I$ aortic valve insufficiency, $A R F$ acute renal failure, $C H F$ congestive heart failure, $S A H$ subarachnoid hemorrhage, $I C H$ intracerebral hemorrhage, Afib atrial fibrillation, $B V A D$ biventricular cardiac assist device, $S R$ sinus rhythm

Former clinical investigations regarding EAdi-catheter positioning refer to the work of Beck [11], where the optimal catheter position was defined by an electromyographic signal from the central electrodes highest in center frequency and reduced in root mean square. Brander [3] additionally judged the correct position by ECG interpretation.

In this study, different information provided by the catheter positioning tool were considered. The anatomical proximity of the right atrium and diaphragm allows an ECG guided positioning of the EAdi-catheter. The progressively decreasing amplitude of the p-wave from the cranial to the caudal electrodes and its absence in the distal lead indicates a position caudal of the right atrium [3]. The catheter positioning tool highlights the leads used for generating the EAdi signal. A catheter position at which the signal for respirator control is taken from the center of the electrode array is advantageous, because displacement of the diaphragm during in- and expiration will most likely not exceed beyond the electrode array. 


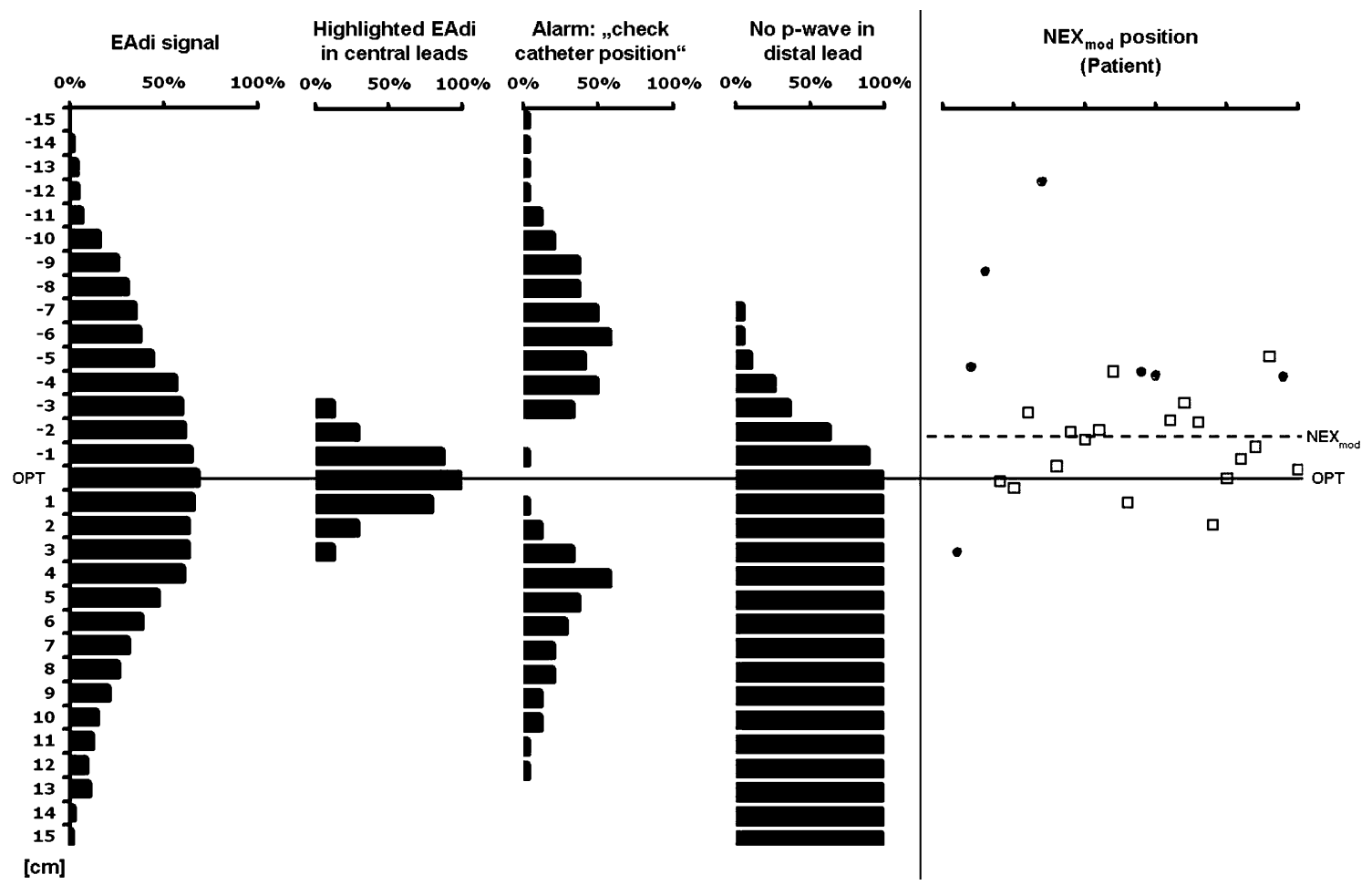

Fig. 1 Comparison of the different procedures of EAdi-catheter positioning in 25 patients. The different variables considered for optimal catheter placement (OPT) (EAdi signal, highlighted EAdi in central leads and no p-wave in lead one) and the ventilators information on bad catheter positioning (Alarm: "check catheter position") are compared to the $\mathrm{NEX}_{\text {mod }}$ method, which is based on anatomical distance measure between xiphoid, earlobe and nose tip. Note: at $\mathrm{NEX}_{\text {mod }}$ NAVA was possible (squares) in $72 \%$ of patients whereas in seven patients (filled circles) NAVA was not possible at NEX $_{\text {mod. }}$ The highlighted EAdi leads and p-wave interpretation indicated an EAdi-catheter position that was too cranial in five patients. In six out of seven patients the "check catheter position" alarm was active. From left to right: EAdi signal: percentage of maximum EAdi signal at different EAdi-catheter insertion

The alarm "check catheter position" appears in this case and proved to be a reliable indicator of a bad catheter position.

We found a median difference of $2 \mathrm{~cm}$ with the OPT situated distal of the $\mathrm{NEX}_{\text {mod }}$ position. Although $\mathrm{NEX}_{\text {mod }}$ and OPT positions were identical in only four patients, running the NAVA mode was possible in 18 patients at $\mathrm{NEX}_{\text {mod }}$ position. The diaphragm forms a muscular "tunnel" of $2-3 \mathrm{~cm}$ covering the oesophagus [12]. This explains why we found stable signals over a certain range and could use NAVA at most NEX $_{\text {mod }}$ positions. However, in seven patients with a NEX $\mathrm{mod}_{\text {mo }}$ OPT difference greater than $3 \mathrm{~cm}$, running NAVA was impossible at $\mathrm{NEX}_{\text {mod }}$ position due to impaired EAdi signal detection. Thus the positioning tool did not only ensure the correct catheter position but also allowed distances. Data were normalized for OPT position and displayed as mean of 25 patients. Highlighted EAdi in central leads: percentage of patients with highlighted EAdi in leads two and three of the catheter positioning tool, normalized for OPT position and displayed as mean of 25 patients. Alarm "check catheter position": percentage of patients with alarm "check catheter position" at different catheter positions. No p-wave in distal lead: percentage of patients with no detectable p-wave in distal lead of the catheter positioning tool normalized for OPT position, displayed as mean of 18 patients; patients NEX $_{\text {mod }}$ position: NEX $_{\text {mod }}$ position of 25 patients in relation to their OPT catheter position. Open squares NAVA was possible in these patients at $\mathrm{NEX}_{\text {mod }}$ position; filled circle NAVA was not possible in these patients at $\mathrm{NEX}_{\text {mod }}$ position

running NAVA in those patients were $\mathrm{NEX}_{\text {mod }}$ failed to predict a good position.

The position of the diaphragm depends on the application of PEEP, body position and intra-abdominal pressure (IAP), respectively [13-15]. The patients included in our study were placed supine with the upper part of the body elevated in a $30^{\circ}$ angle for catheter positioning and had a median PEEP level of $8 \mathrm{cmH}_{2} \mathrm{O}$. Pressure support ventilation with zero PEEP compared to a PEEP level of $10 \mathrm{~cm} \mathrm{H}_{2} \mathrm{O}$ results in a $2 \mathrm{~cm}$ shift caudal regarding the middle part of the diaphragm [14]. Although we didn't measure intra-abdominal pressure there was no clinical suspicion of such. The body position and application of PEEP may have contributed to the fact, that OPT position was found distal of the $\mathrm{NEX}_{\mathrm{mod}}$ position. 


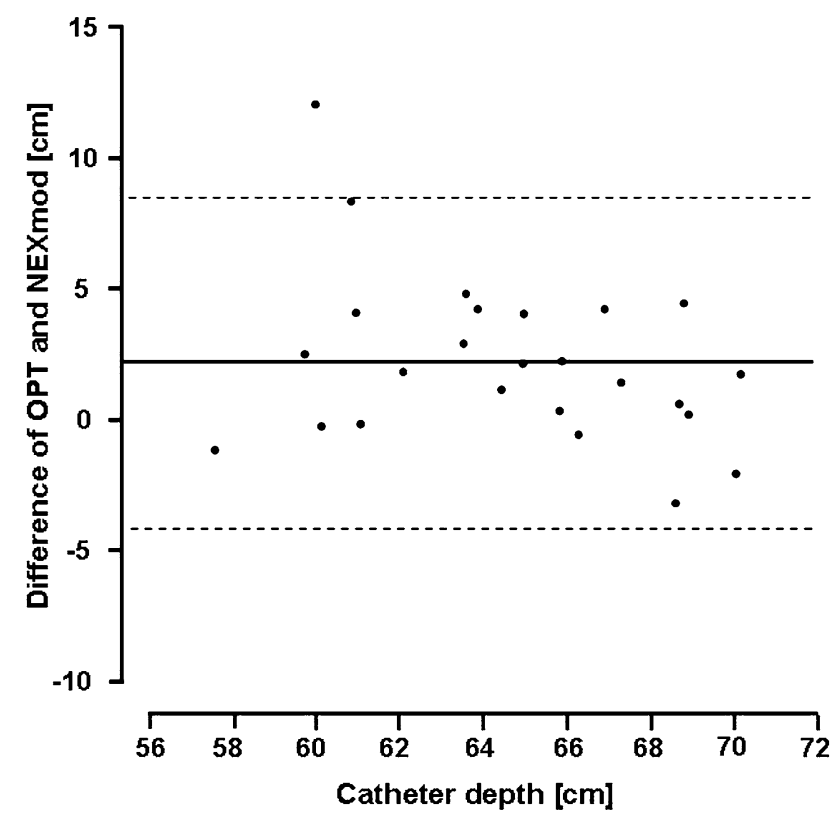

Fig. 2 Bland-Altman plot. Plot of difference of OPT and NEX against mean of OPT and $\mathrm{NEX}_{\text {mod. }}$ Solid line shows mean of difference, dotted line shows mean \pm 2 SD. [16] The figure shows a mean difference of $2.2 \mathrm{~cm}$ between OPT and NEX $\mathrm{Nod}_{\text {and one }}$ outlier

In one patient missing EAdi led to the diagnosis of bilateral phrenic nerve injury. The patient with suspected
Laurence-Moon-Biedl-Bardet-Syndrom represented an obvious problem with $\mathrm{NEX}_{\text {mod }}$ calculation that was predictable due to the askew anatomy. In one patient (post gastric surgery) the catheter positioning tool did not provide reliable data, nevertheless we were able to treat the patient with NAVA. Thus gastric surgery might be considered as a relative contraindication for EAdi-catheter placement.

\section{Conclusion}

Positioning the EAdi-catheter using $\mathrm{NEX}_{\text {mod }}$ gives a good approximation of the catheter position in most patients. The additional tools for catheter positioning are needed to ensure an optimal position, especially in those patients were $\mathrm{NEX}_{\text {mod }}$ fails. Further studies based on a larger set of patients are required to enhance the accuracy of the NEX formula taking into account PEEP, body position and IAP, respectively.

Open Access This article is distributed under the terms of the Creative Commons Attribution Noncommercial License which permits any noncommercial use, distribution, and reproduction in any medium, provided the original author(s) and source are credited.

\section{References}

1. Sinderby C, Navalesi P, Beck J, Skrobik Y, Comtois N, Friberg S, Gottfried SB, Lindstrom L (1999) Neural control of mechanical ventilation in respiratory failure. Nat Med 5:1433-1436

2. Colombo D, Cammarota G, Bergamaschi V, De Lucia M, Corte FD, Navalesi P (2008) Physiologic response to varying levels of pressure support and neurally adjusted ventilatory assist in patients with acute respiratory failure. Intensive Care Med 34:2010 2018

3. Brander L, Leong-Poi H, Beck J, Brunet F, Hutchison SJ, Slutsky AS, Sinderby C (2009) Titration and implementation of neurally adjusted ventilatory assist in critically ill patients. Chest 135:695-703

4. Allo JC, Beck JC, Brander L, Brunet F, Slutsky AS, Sinderby CA (2006) Influence of neurally adjusted ventilatory assist and positive endexpiratory pressure on breathing pattern in rabbits with acute lung injury. Crit Care Med 34:2997-3004
5. Beck J, Campoccia F, Allo JC, Brander L, Brunet F, Slutsky AS, Sinderby C (2007) Improved synchrony and respiratory unloading by neurally adjusted ventilatory assist (NAVA) in lung-injured rabbits. Pediatr Res 61:289-294

6. Moerer O, Beck J, Brander L, Costa R, Quintel M, Slutsky AS, Brunet F, Sinderby C (2008) Subject-ventilator synchrony during neural versus pneumatically triggered non-invasive helmet ventilation. Intensive Care Med 34:1615-1623

7. Moerer O, Barwing J, Quintel M (2008) Neurally adjusted ventilatory assist (NAVA). A new mode of assisted mechanical ventilation. Anaesthesist 57:998-1005

8. Hanson RL (1979) Predictive criteria for length of nasogastric tube insertion for tube feeding. J Parenter Enter Nutr 3:160-163

9. Kranke B, Januschowski R, Balzer K (1993) Laurence-Moon-Bardet-Biedl syndrome. Med Klin (Munich) 88:7881
10. Moore SJ, Green JS, Fan Y, Bhogal AK, Dicks E, Fernandez BA, Stefanelli M, Murphy C, Cramer BC, Dean JC, Beales PL, Katsanis N, Bassett AS, Davidson WS, Parfrey PS (2005) Clinical and genetic epidemiology of Bardet-Biedl syndrome in Newfoundland: a 22-year prospective, population-based, cohort study. Am J Med Genet A 132:352-360

11. Beck J, Sinderby C, Lindstrom L, Grassino A (1996) Influence of bipolar esophageal electrode positioning on measurements of human crural diaphragm electromyogram. J Appl Physiol 81:1434-1449

12. Delattre JF, Palot JP, Ducasse A, Flament JB, Hureau J (1985) The crura of the diaphragm and diaphragmatic passage: applications to gastroesophageal reflux, its investigation and treatment. Anat Clin 7:271-283

13. Malbrain ML (2004) Is it wise not to think about intra-abdominal hypertension in the ICU? Curr Opin Crit Care 10:132-145 
14. Froese AB, Bryan AC (1974) Effects of 15. Mutoh T, Lamm WJ, Embree LJ, anesthesia and paralysis on diaphragmatic mechanics in man. Anesthesiology 41:242-255
Hildebrandt J, Albert RK (1991)

Abdominal distension alters regional pleural pressures and chest wall mechanics in pigs in vivo. $\mathbf{J}$ Appl Physiol 70:2611-2618
16. Bland JM, Altman DG (1986) Statistical methods for assessing agreement between two methods of clinical measurement. Lancet 8:307310 